Etnográfica

Revista do Centro em Rede de Investigação em

Antropologia

vol. 21 (3) | 2017

Vol. 21 (3)

\title{
Escolher, cuidar e proteger: masculinidade e dinâmicas familiares em Marrocos
}

To choose, care and protect: masculinity and family dynamics in Morocco

\section{Raquel Carvalheira}

\section{(2) OpenEdition}

\section{Journals}

\section{Edição electrónica}

URL: https://journals.openedition.org/etnografica/5078

DOI: 10.4000/etnografica.5078

ISSN: 2182-2891

\section{Editora}

Centro em Rede de Investigação em Antropologia

\section{Edição impressa}

Data de publição: 1 outubro 2017

Paginação: 613-625

ISSN: 0873-6561

\section{Refêrencia eletrónica}

Raquel Carvalheira, «Escolher, cuidar e proteger: masculinidade e dinâmicas familiares em Marrocos», Etnográfica [Online], vol. 21 (3) | 2017, posto online no dia 24 março 2018, consultado o 10 fevereiro 2022. URL: http://journals.openedition.org/etnografica/5078; DOI: https://doi.org/10.4000/ etnografica. 5078

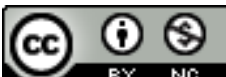

Etnográfica is licensed under a Creative Commons Attribution-NonCommercial 4.0 International License. 


\section{Escolher, cuidar e proteger: masculinidade e dinâmicas familiares em Marrocos}

\section{Raquel Carvalheira}

Este artigo discute as relações de género em Marrocos, por via da análise de três relatos masculinos, dois sobre o casamento e um sobre o investimento pessoal na educação das irmãs. O principal objetivo é questionar a masculinidade como um processo social e histórico que permite pensar a interação entre estruturas continuadas de dominação masculina e a transformação dos modos de vida, valores e formas de organização familiar. Em Marrocos, a dessegregação do espaço público, a crescente urbanização e a integração progressiva da mulher no mercado de trabalho assalariado são alguns ingredientes, entre outros, que têm contribuído para modificar as relações entre homens e mulheres no interior da família. As histórias apresentadas são pontos de partida para aferir as tensões, limitações e negociações quotidianas inerentes ao processo de construção da masculinidade e da feminilidade, e ainda para desmontar leituras dicotómicas sobre as relações de poder entre géneros.

PALAVRAS-CHAVE: Marrocos, relações de género, masculinidade, família, casamento, educação.

To choose, care and protect: masculinity and family dynamics in Morocco - This article discusses gender relations in Morocco through the analysis of three male accounts: two of marriage and one of a man's personal investment in his sisters' education. Its main objective is to analyse masculinity as a social and historical process and to understand the interaction between enduring structures of male domination and changing ways of life, values and forms of family organization. In Morocco, the desegregation of public space, increasing urbanization and progressive integration of women into the wage-labour market are among the factors which have contributed to shifts in the relationships between men and women within the family unit. The accounts featured in this article serve as starting points for assessing the tensions, limitations and daily negotiations inherent to the process of constructing masculinities and femininities, as well as for dismantling dichotomous readings of gender power relations.

KEYWORDS: Morocco, gender relations, masculinity, family, marriage, education.

CARVALHEIRA, Raquel (raquelcarvalheira@gmail.com) - Centro em Rede de Investigação em Antropologia (CRIA/NOVA FCSH), Faculdade de Ciências Sociais e Humanas, Universidade Nova de Lisboa, Portugal. 


\section{INTRODUÇÃO}

$\mathrm{Na}$ introdução de um número da revista Al-Raida totalmente dedicado às questões da masculinidade no Norte de África e no Médio Oriente, Aghacy (2004) menciona a ausência de uma leitura crítica sobre o género masculino nas ciências sociais e humanas e descreve o retrato simplista que frequentemente é produzido sobre os homens, apresentados como figuras monolíticas que oprimem as mulheres e que lhes negam o acesso aos seus direitos. ${ }^{1}$ Uma parte significativa da literatura sobre género nesta região tem focado sobretudo a construção de identidades de género femininas num contexto de fortes desigualdades (Kapchan 1996; Macleod 1991; Mahmood 2005; Mernissi 2011 [1985]; Newcomb 2009; Silva 1999; Žvan-Elliot 2015; entre outros). Urge centrar a discussão na construção da masculinidade, entendendo-a como um processo histórico e social.

Este artigo tem por objetivo oferecer alguns dados que possam enriquecer esta discussão, olhando em particular para os relatos de três homens, dois deles em torno do casamento e um outro sobre o investimento pessoal na educação das irmãs. Pretende-se esboçar aqui um esquema aproximativo das perspetivas e das expectativas em relação ao casamento e às responsabilidades familiares de uma primeira geração de homens a viver em contexto urbano e, além disso, oriundos de famílias sem grandes recursos económicos e capitais sociais e culturais. O material etnográfico foi recolhido durante a pesquisa de doutoramento conduzida na cidade de Essaouira, em Marrocos, em 2010 e 2012. Como adiante veremos, a masculinidade em Marrocos é um processo ambíguo e cheio de contradições, na medida em que assenta numa pressão social incutida nos homens tendo em vista o cumprimento do dever de sustentar, cuidar e prover a família, num contexto marcado por enormes clivagens sociais e económicas e por uma crescente participação das mulheres no espaço público e no trabalho assalariado. Com efeito, cada vez mais mulheres estudam e contribuem economicamente para os seus agregados domésticos, o que tem obrigado também os homens a reposicionarem-se socialmente face a tais transformações. Os relatos apresentados ilustram esse reposicionamento, o qual só pode ser verdadeiramente entendido se tomarmos em consideração dinâmicas mais estruturais, que são indispensáveis para uma análise do papel dos homens como sujeitos e agentes de mudança.

1 Este artigo resulta de uma investigação de doutoramento em Antropologia Social e Cultural, especialidade em Antropologia do Género e do Parentesco, conduzida entre 2009 e 2015 no Instituto de Ciências Sociais da Universidade de Lisboa, com orientação do Prof. Dr. João de Pina Cabral e da Prof. ${ }^{a}$ Dr. ${ }^{a}$ Maria Cardeira da Silva (Carvalheira 2015). Agradeço os comentários ao artigo por parte do/a avaliador/a e também ao João Pedro George e à Diana Lixandru pelas sugestões de alteração ao texto. 


\section{"RAPARIGAS DA CIDADE E RAPARIGAS DO CAMPO": DISCURSOS SOBRE A ESCOLHA MATRIMONIAL}

Em Marrocos, assiste-se a alterações importantes ao nível do casamento, algumas com relevância estatística - como a redução do tamanho dos agregados domésticos e do número de filhos, o recuo da idade do primeiro casamento e o crescimento do celibato (Lfarakh 1998; Ajbilou s. d. [2005]) - e outras que serão talvez impossíveis de captar sem o recurso à análise etnográfica. Um dos aspetos mais discutidos na literatura refere-se à maior importância que tem sido atribuída à escolha pessoal no casamento e à ideologia do amor romântico, vistas como oferecendo um acréscimo de liberdade individual face às tradicionais obrigações para com a família (Mernissi 2011 [1985], 2007; Newcomb 2009). Aliás, a integração das mulheres no mercado de trabalho assalariado tem permitido que muitos homens e mulheres se conheçam e, nesse processo, o peso da família tem sido reconfigurado, integrando cada vez mais as escolhas pessoais. Bennani-Chraïbi (1995) e Gandolfi (2015) demonstraram que muitos jovens questionam os modelos hegemónicos de família, baseados na autoridade dos pais e dos mais velhos. No entanto, apesar destas transformações, a história de Jamil indica que alguns jovens parecem continuar a confiar a escolha de uma esposa nas mãos de outros membros da família.

Jamil tomava conta de uma oficina de automóveis em Essaouira, onde eu costumava deixar o meu carro. Um dia, visivelmente emocionado, aproximou-se do carro e contou-me que provavelmente iria casar. Tinha vivido, até então, na garagem e conseguira poupar algum dinheiro, o suficiente, dizia, para comprar uma casa em Essaouira (algo que, para muitos homens, constitui um dos primeiros passos na constituição de uma nova unidade doméstica). Tinha 24 anos e não queria continuar a viver na oficina, precisava de uma família, dizia. Certa manhã, Jamil correu sobressaltado para o carro e contou-me que a mãe e a irmã tinham encontrado uma rapariga no campo, de mais a mais bonita, segundo a descrição delas. Os pais viviam na zona rural de Essaouira, onde conheciam uma família que tinha uma filha jovem e solteira. Perguntei-lhe porque depositava a escolha da mulher na irmã e na mãe, ao que me respondeu que elas tinham contacto com mulheres, coisa que ele, naquele universo masculino da garagem, não conseguia. Além disso, conhecer diretamente uma rapariga e sair com ela não era por si só garantia de que estaria perante uma boa esposa. A sua mãe dizia-lhe que não deveria casar com uma rapariga da cidade porque essas mulheres aspiram a uma maior liberdade de movimentos. Uma rapariga do campo seria preferível, pois ainda eram educadas "dentro da família” (ou seja, não iam à escola e aprendiam os afazeres domésticos). Para Jamil, não deveria ser ele a encontrar uma mulher, não apenas porque a sua vivência num ambiente por definição masculino não lho permitia, mas também porque aceitava a premissa geral de que a melhor escolha seria sempre a da sua mãe. 
A predileção por uma esposa oriunda de um meio descrito como tradicional evidencia uma recusa de determinadas transformações sociais entendidas como tipicamente urbanas, como o maior contacto entre homens e mulheres e o facto de muitas mulheres procurarem uma maior liberdade de movimentos e autonomia pessoais. Para tal contribuíram as rápidas mudanças sociais desencadeadas pelo êxodo rural em Marrocos, sobretudo para as populações analfabetas e empobrecidas que se fixaram nas cidades. As estatísticas oficiais indicam que nos anos 60 apenas $29 \%$ da população vivia em contextos urbanos; em 2014 a percentagem era já de $59 \% .^{2}$ As disparidades entre os contextos rurais e urbanos fazem-se sentir ao nível das oportunidades de trabalho e do acesso a serviços, meios de comunicação, cuidados de saúde e educação (Crawford 2008; Žvan-Elliot 2015), razões mais do que bastantes para que muitos jovens como Jamil tentem a sua sorte nas cidades.

De acordo com Aboumalek (1994), no inquérito conduzido em Casablanca nos anos 90 era notória uma preferência dos citadinos oriundos de zonas rurais pelo casamento com alguém do mesmo local de origem, uma prática comum entre as camadas mais pobres, sem outro tipo de recursos e sem redes sociais na cidade. Dessa preferência se deduzia que as disparidades se faziam também sentir ao nível das escolhas matrimoniais, onde estatuto social, instrução e local de origem são fatores com peso. As redes de proximidade, de vizinhança e de parentesco permitem fazer face à experiência do anonimato causada pela vivência na cidade e pela integração numa economia de mercado caracterizada pela instabilidade e pela precariedade.

Žvan-Elliot (2015) considera que a sociedade rural marroquina não tem sido objeto de políticas públicas que promovam a igualdade de género e que muitas raparigas e mulheres, mesmo as que estudaram, não dispõem daquelas oportunidades que lhes permitiriam enfrentar um sistema patriarcal. A marginalização e a falta de oportunidades laborais, tanto nas zonas rurais como nas zonas urbanas, favorecem a ideia de que as mulheres devem permanecer em casa, para não roubarem os empregos aos homens e de modo a permitirem que estes assumam o papel socialmente esperado de sustentáculo da família. Os resultados de um inquérito conduzido em Marrocos exprimem esta perceção: $73 \%$ dos homens e $71 \%$ das mulheres consideram que, quando os empregos são escassos, os homens devem ter um acesso privilegiado ao mercado de trabalho (El Feki, Heilman e Barker 2017). Estas percentagens indicam que, apesar de cada vez mais mulheres trabalharem como assalariadas, este tipo de atividade é entendido como uma obrigação masculina.

2 Dados do recenseamento geral de 2014, disponíveis no website do Haut Comissariat au Plan do Reino de Marrocos, < http://www.hcp.ma/Presentation-des-premiers-resultats-du-RGPH-2014_al605. html > (última consulta em outubro de 2017). 
Ainda assim, muitos rapazes e raparigas de contextos rurais tentam libertar-se de determinados constrangimentos familiares e sociais - é essa, pelo menos, a leitura de Crawford (2008), que realizou trabalho de campo numa aldeia das montanhas do Atlas. Utilizando uma perspetiva longitudinal, o autor mostra como as cidades se tornaram atrativas para os jovens, que procuram uma maior independência face aos patriarcas das famílias e pretendem libertar-se dos trabalhos agrícolas, pouco rentáveis do ponto de vista monetário e fisicamente muito exigentes. Devido às condições difíceis da vida no campo, muitas famílias investem grandes quantias de dinheiro no casamento das filhas com homens da cidade, na que é tacitamente assumida por todos como a melhor estratégia para alcançar um maior estatuto social, decorrente, em parte, da dedicação exclusiva à vida doméstica (não precisando se a articular com o trabalho agrícola) e do acesso a bens de consumo (Maher 1974; Žvan-Elliot 2015). Muitas raparigas oriundas de contextos rurais empregam-se também nas cidades e anseiam poder ser parte ativa na condução das negociações relativas ao casamento (Crawford 2008).

Os interesses e expectativas de muitas famílias no campo consistem em casar uma filha com alguém estabelecido na cidade. Por outro lado, o sucesso económico de um rapaz e da sua família materializa-se também na capacidade daquele para conseguir manter uma unidade doméstica em que a mulher é doméstica e não precisa de se submeter ao trabalho assalariado, que uma parte significativa da população, em particular as franjas mais empobrecidas e ruralizadas, considera desprestigiante para as mulheres, pois estimula o contacto sempre indesejado com homens desconhecidos. A ideia generalizada de que a mulher deve assumir maioritariamente o trabalho doméstico, nas suas múltiplas dimensões, e de que ao homem compete trabalhar fora de casa encontra eco nos resultados do Inquérito Nacional de Valores (Rachik et al. s. d. [2005]). Em Marrocos, uma das características mais valorizadas na escolha de uma esposa é que seja hadga, um termo do árabe coloquial marroquino utilizado para descrever as mulheres que se empenham vivamente nos seus afazeres domésticos; para a escolha do esposo ideal, o mais importante é ter um rendimento estável. Outras características são igualmente valorizadas, mas é de notar que muitos marroquinos e muitas marroquinas têm uma visão partilhada relativamente aos diferentes papéis de género no interior do casamento.

A oposição entre as raparigas da cidade e as raparigas do campo enunciada por Jamil encontra explicação numa ideologia que tende a reforçar as diferenças entre contextos urbanos e rurais e que advoga que o campo conserva um estilo de vida tradicional face à cidade, palco das modernidades menos desejadas. Muitas das discussões que antecederam a reforma do Código de Estatuto Pessoal em Marrocos, em 2004, um processo importante que garantiu uma maior igualdade legal entre homens e mulheres no casamento e na vida familiar, 
tinham como alvo principal a posição social das mulheres face às mudanças da sociedade marroquina (Ramírez 2005-2006). Alguns setores mais conservadores defendiam o mundo rural como reduto da família tradicional, onde homens e mulheres eram complementares, e criticavam as mulheres da classe média-alta das cidades por quererem impor modelos de famílias importados do "Ocidente" ${ }^{3} \mathrm{Na}$ construção destas narrativas intervêm também interpretações concorrentes do Islão, sendo o crescimento de uma ideologia mais estrita do ponto de vista das relações de género um fator não despiciendo da análise. A oposição entre o que é tradicional e moderno (na família e nos comportamentos de género) encontra assim eco no discurso de Jamil e nas suas expectativas tendo em vista o casamento. A procura de uma esposa é conduzida pelas mulheres, o que patenteia não só o papel importante destas nas escolhas matrimoniais, como também o facto de serem elas as responsáveis pela reprodução de determinadas conceções de género, entre as quais avultam as divisões entre raparigas da cidade e raparigas do campo.

\section{IDEAL CONJUGAL HEGEMÓNICO: EXPECTATIVAS E DESENCONTROS}

Várias gerações no período pós-independência de Marrocos têm encarado a educação escolar e universitária como um bem universal e o motor de uma mobilidade social ascendente (Bennani-Chraïbi 1995). Salim, de 42 anos, foi o primeiro entre os irmãos a fazer uma licenciatura, um período da sua vida que recorda saudosamente e que o iniciou na mobilização política, sendo ainda hoje membro da Associação Marroquina dos Direitos Humanos (AMDH). Era um ativista que acreditava e defendia a igualdade de direitos entre homens e mulheres. Depois de finalizar o curso, regressou a Essaouira e experimentou algum tempo de inatividade, até que resolveu trabalhar, durante algum tempo, como empregado em vários cafés e hotéis turísticos da cidade. Como o pai tinha um terreno na região de Essaouira, Salim começou a trabalhar no projeto para a construção de um parque de campismo, o que implicou a realização de um estudo intensivo que incluiu a elaboração de plantas minuciosas da disposição do espaço, indicações dos esgotos, das passagens de água e dos fios elétricos, e até uma descrição pormenorizada da singularidade ecológica do espaço. Tudo isso consumiu muito do seu tempo e dinheiro. Depois de cinco anos de espera, a municipalidade de Essaouira recusou a Salim a licença para a construção do parque de campismo, com base no argumento de que incidia sobre uma zona protegida. No entanto, dizia-me, várias outras construções existem naquela região e, por essa razão, achava que se devia à falta de baqchich (o pagamento de uma quantia "extra" que permitisse a aceitação da obra)

3 Ver artigo de opinião "Point de vue de Mahjoubi Aherdane et du dr. Al Khatib: notre mise au point concernant le plan d'action”, Le Reporter, 1999. 
ou de "cunhas" (recomendações de pessoas influentes). Voltou a trabalhar como empregado em hotéis e restaurantes para turistas e juntou assim algum dinheiro para começar um negócio próprio - um café -, de que é proprietário hoje em dia.

Durante as décadas de 1980 e 1990, Marrocos foi sujeito a programas de ajustamento estrutural por parte do FMI e do Banco Mundial, que muito contribuíram para a retração da economia marroquina e para a incapacidade do Estado para empregar uma população recentemente educada (Vermeren 2011). A importância da economia informal, baseada na sazonalidade e na precariedade laboral, continua a dificultar a absorção de mão-de-obra qualificada, o que explica o facto de o desemprego afetar sobretudo os setores mais instruídos da população: o Inquérito Nacional sobre o Emprego conduzido pelas entidades marroquinas indica que, em 2014, 21,1\% dos desempregados tinham o nível superior, 15,5\% o nível intermédio e 4,7\% não possuíam qualquer diploma. Estes dados são ainda mais relevantes tendo em conta que, nesse mesmo ano, $45,1 \%$ da população era iletrada. ${ }^{4}$

As políticas de austeridade atingiram sobretudo uma geração que investiu na educação e uma classe média que começava a formar-se (Cohen 2004). A Associação de Diplomados no Desemprego de Marrocos formou-se no rescaldo destes acontecimentos e tornou-se um dos movimentos sociais mais importantes em Marrocos (Emperador Badimon 2009). Generalizou-se também a crítica à corrupção, existente em várias esferas da vida social e política do país, e a perceção de que os bons empregos eram atribuídos, não pelo mérito, mas pelas redes de relações com o poder. A história de Salim dá conta destas transformações estruturais na economia e sociedade marroquinas e aponta para a "crise de masculinidade" descrita por muitos autores em Marrocos, como Dialmy (2009), El Feki, Heilman e Basker (2017) e Perkins (2004). Depois de terminados os estudos, Salim queria casar-se com uma colega da universidade; no entanto, como não tinha trabalho, o pai da rapariga recusou. Mais tarde, e já em Essaouira, uma outra proposta acabou por não chegar a bom porto quando Salim se recusou a fazer a festa de casamento, possivelmente porque não tinha meios para pagar o investimento que implicava e porque se tratava, na sua opinião, de um desperdício financeiro incomensurável. Para a família da noiva, porém, era uma condição indispensável. Aos 42 encetou de novo negociações para o casamento, mas a idade parecia colocá-lo agora em desvantagem.

A "crise de masculinidade" é vivida por muitos daqueles que sentem dificuldades económicas mas que querem assumir o seu papel como homens

4 Os dados apresentados provêm de "Femmes et hommes en chiffres", no website do Haut-Comissariat au Plan, disponível em < https://www.hcp.ma/region-drda/attachment/657245/> (última consulta em outubro de 2017). 
capazes de sustentar a família, uma expectativa que continua a ser alimentada por muitos homens, mulheres e famílias. Na década de 90, Mir-Hosseini (2000 [1993]) demonstrou que muitas das disputas matrimoniais levadas a tribunal em Rabat e Casablanca estavam relacionadas com o choque entre um modelo de casamento baseado na ideia do homem como sustento da casa e o facto de muitas mulheres terem de trabalhar para os seus agregados domésticos. Muitas famílias apenas aceitam casar as filhas com pretendentes que apresentem trabalho fixo e estável, o que obriga muitos homens a adiar o casamento. Nos últimos 50 anos, tanto homens como mulheres têm vindo progressivamente a casar cada vez mais tarde: em 1960, a idade média do casamento dos homens andava nos 24 anos e em 2014 passou para os 31 anos (Ajbilou s. d. [2005]). ${ }^{5}$

Apesar da liberdade de movimentos e das mudanças conquistadas por muitas mulheres no espaço público, a informalidade e a precariedade do trabalho também as afetam, daí que muitas delas anseiem por encontrar um marido que assuma aquilo que é socialmente esperado deles e prefiram abandonar os empregos para se dedicarem exclusivamente à casa e aos filhos (Carvalheira 2016). Dito de outro modo, as expectativas continuam a ser muito difíceis de cumprir em circunstâncias onde existem poucos apoios sociais do Estado às jovens famílias (Chekroun 1996; Daoudi 1998); por essa razão, o ideal de uma masculinidade hegemónica (cf. Almeida 1995) acaba por exercer uma pressão social sobre os homens, vítimas de uma situação que supostamente lhes dá um papel privilegiado nas tomadas de decisão.

Em suma, o percurso de Salim demonstra que o projeto de ascender socialmente através da educação tende a ser contrariado pelas próprias circunstâncias de vida em Marrocos, o que contribui decisivamente para baixar as expectativas de muitos homens de alcançarem a vida conjugal. Salim tinha agora orgulho no seu café, onde tentava construir uma pequena biblioteca e lamentava o desinteresse da sua clientela pelos livros, preferindo usar o espaço para beber cafés ou jogar cartas e dominó. Defendia, apesar da sua própria história, a educação como um instrumento que permite às pessoas pensar e questionar a sua própria condição.

\section{IRMÃOS E IRMÃS: INVESTIMENTO PESSOAL, HONRA E EDUCAÇÃO}

Youssef, de 30 anos, também possui um curso universitário e é desempregado. Afirma que a família se fixou em Essaouira quando ele ainda não tinha nascido e que, desde cedo, os rapazes faziam pequenos trabalhos fora de casa, no porto,

5 Dados corroborados por informação do Haut-Comissariat au Plan, "Femmes et hommes en chiffres", disponível em < https://www.hcp.ma/region-drda/attachment/657245/> (última consulta em outubro de 2017). 
a vender cigarros, durante as épocas de maior afluência de turistas, para ajudar a pagar os estudos dos irmãos e das irmãs mais novas. As raparigas ficavam habitualmente em casa e os rapazes juntavam dinheiro para comprar o material escolar das irmãs. Estes pequenos trabalhos eram assumidos como necessários para proteger as irmãs das dificuldades da vida, o que desenvolveu entre os rapazes um sentimento de proteção e cuidado. Youssef entendia que era sua obrigação cuidar das irmãs e dar-lhes tudo aquilo de que elas precisavam. Ele tinha sido o responsável pela educação de uma das suas irmãs mais novas, que concluiu os estudos e se tornou professora primária em 2013, o que para ele era motivo de grande orgulho.

Muito embora as expectativas educacionais tenham, em termos de emprego, sido defraudadas, a maior parte das famílias, pelo menos em contextos urbanos, esforça-se por enviar as filhas para a escola. Youssef reconhecia que, na sua família, a educação era encarada como necessária, tanto para os rapazes como para as raparigas, porém, no que tocava à liberdade de sair de casa, as coisas eram bem diferentes. $\mathrm{Na}$ realidade, em Marrocos, os resultados do inquérito conduzido recentemente pelas Nações Unidas sobre as masculinidades (El Feki, Heilman e Barker 2017) espelham este tipo de posições: mais de três quartos dos homens entrevistados apoiam a igualdade educacional para homens e para mulheres e quase $90 \%$ dos inquiridos do sexo masculino referiu deter maior liberdade de movimentos do que as suas irmãs, embora tivessem perdido parte do seu tempo de lazer, na juventude, porque a família depositava neles a tarefa de ganhar dinheiro para a casa. O discurso de Youssef exprimia a importância que ele dava à educação da irmã mais nova, talvez tentando mostrar que também ele acreditava que as mulheres eram merecedoras de um projeto de vida considerado emancipatório.

Joseph (1999) demonstrou que a relação entre irmãos e irmãs é a mais próxima que existe entre géneros em contextos onde a segregação é ideologicamente relevante. As diferenças de género estabelecem assimetrias entre pessoas - neste caso, entre homens e mulheres -, mas são também um processo de constituição de laços de parentesco, expressos numa linguagem de amor, cuidado e proteção. Youssef acreditava, como muitos daqueles que foram inquiridos no estudo supracitado, que a maior liberdade de movimentos lhe tirou tempo de lazer, mas que esse tempo foi utilizado para investir num projeto de vida que considerava de grande valor: a educação das irmãs. A maior honra que sentia como irmão já não era o facto de conseguir proteger a irmã do mundo exterior, mas conseguir trabalhar para que ela pudesse estudar sem enfrentar qualquer tipo de constrangimentos económicos.

Žvan-Elliot (2017) defende que a educação escolar pode não ser um projeto emancipatório para muitas raparigas que enfrentam conceções tradicionalistas em relação ao género. Ou seja, o casamento continua a ser visto como o evento mais importante na vida de qualquer rapariga e a educação é encarada como 
um investimento para casar melhor, com alguém de estatuto social e económico superior. Por essa razão, a autora refere a importância de uma análise crítica relativamente aos discursos sobre o papel da educação na emancipação das mulheres, tantas vezes mobilizados pelas agências de desenvolvimento. É preciso não esquecer que, para muitos marroquinos e muitas marroquinas, a educação das filhas e das irmãs é uma questão de honra, porque não querem vê-las excluídas de fazer face a um mundo em mudança.

Assim, a narrativa de Youssef permite identificar valores que noutros contextos poderiam ser considerados contraditórios: o desejo de proteger as irmãs é baseado em sentimentos como o cuidado, a honra e, consequentemente, a vigilância sobre a exposição pública feminina. Por outro lado, os rapazes investem com sacrifício pessoal na educação das irmãs, uma atividade que decorre frequentemente em ambientes dessegregados e que lhes pode garantir uma vida melhor. Ora, como se pode ver, existem jovens marroquinos que se posicionam favoravelmente às mudanças sociais que afetam muitas mulheres, embora o façam dentro de um quadro cultural e social que os impele a comportamentos de proteção da honra (das raparigas e da família) tipicamente masculinos. A narrativa de Youssef é, por isso, indicativa da complexidade e da dificuldade de catalogar os homens como sujeitos ativos no bloqueio das liberdades femininas.

\section{CONCLUSÃO}

As histórias aqui apresentadas pretendem contribuir para uma reflexão sobre a experiência diversificada das vivências masculinas em Marrocos. Como se pôde verificar pelos relatos de Jamil, de Salim e de Youssef, existem valores sociais relativamente ao que é ser homem e mulher que não são independentes de outros fatores, nomeadamente políticos, sociais, económicos e geográficos. A história de Jamil ilustra que as relações entre campo e cidade são indispensáveis para compreender determinadas ideologias que configuram as escolhas matrimoniais. Apesar da crescente importância das preferências pessoais no casamento, muitos jovens preferem depositar a escolha do cônjuge nas mãos de outros membros da família, o que poderá pôr em causa o pressuposto de que o casamento deveria ser o resultado de um envolvimento íntimo e amoroso entre duas pessoas. Este tipo de procura matrimonial afeta tanto homens como mulheres em contextos onde a segregação continua a ser um fator estrutural de primeira magnitude. Por outro lado, a história de Salim exemplifica os insucessos que muitos homens enfrentam na tentativa de contraírem matrimónio. A sua história corresponde à de muitos outros marroquinos que sofreram o desemprego depois de terem investido na educação com a expectativa de, no futuro, conseguirem um trabalho estável e bem pago que lhes permitisse assumir o papel socialmente esperado na família. 
Aos 42 anos, Salim ainda lutava para conseguir reunir as condições necessárias para se casar. A trajetória de Youssef, por outro lado, mostra que os comportamentos considerados tipicamente masculinos (de proteção da honra da família através da modéstia das irmãs) têm subjacente um projeto que visa a emancipação das irmãs.

Para concluir, resta-nos sublinhar a necessidade de se desmontar algumas das grelhas de análise mais comuns sobre a masculinidade em Marrocos e em muitos países muçulmanos e perceber também que tanto a situação como a condição dos homens merecem maior atenção quando se pretende compreender os direitos e liberdades pessoais. Porém, e como se viu, esses direitos e liberdades são vividos e pensados quer por homens quer por mulheres. Daí que os exemplos apresentados neste artigo procurem chamar a atenção para as diferentes referências sociais e culturais que estão em jogo na construção da masculinidade e da feminilidade, bem como descrever conjunturas específicas de mudança onde ocorrem as negociações das relações de género.

\section{BIBLIOGRAFIA}

ABOUMALEK, Mostafa, 1994, Qui épouse qui: Le mariage en milieu urbain. Casablanca, Afrique Orient.

AGHACY, Samira, 2004, "What about masculinity?", Al-Raida, 21 (104-105): 11, disponível em < http://iwsaw.lau.edu.lb/publications/al-raida/al-raida-what-about-masculinity. php $>$ (última consulta em outubro de 2017).

AJBILOU, Aziz (org.), s.d. [2005], Démographie marocaine: tendances passées et perspectives d'avenir. Rapport thématique, s.1., Centre d'Etudes et des Recherches Demographiques, disponível em < http://www.abhatoo.net.ma/content/download/18719/336588/version/1/file/ D\%C3\%A9mographie + Marocaine+. + tendances + pass\%C3\%A9es+et+ perspectives+d\%E2\%80\%99avenir.pdf > (última consulta em outubro de 2017).

ALMEIDA, Miguel Vale de, 1995, Senhores de Si: Uma Interpretação Antropológica da Masculinidade. Lisboa, Fim de Século.

BENNANI-CHRAÏBI, Mounia, 1995, Soumis et rebelles: Les Jeunes au Maroc. Casablanca, Editions Le Fennec.

CARVAlHEIRA, Raquel Gil, 2015, Autoridade e Autonomia: Conjugalidade e Vidas Femininas em Essaouira, Marrocos. Lisboa, Instituto de Ciências Sociais da Universidade de Lisboa, tese de doutoramento em Antropologia Social e Cultural.

CARVALHEIRA, Raquel Gil, 2016, "Changing family strategies in contemporary Morocco: women's stories, persistent ideologies and matrimonial strategies", Ethnologia Europaea, 46 (1): 58-75. 
CHEKROUN, Mohamed, 1996, Famille, Etat et transformations socio-culturelles au Maroc. Rabat, Editions Okad.

COHEN, Shana, 2004, Searching for a Different Future: The Rise of a Global Middle Class in Morocco. Durham, Duke University Press.

CRAWFORD, David, 2008, Moroccan Households in the World Economy: Labour and Inequality in a Berber Village. Baton Rouge, LA, Louisiana State University Press.

DAOUDI, Lahcen, 1998, "La famille, ses droits, sa composition et sa structure - appui socio-économique à la famille”, em Démographie: Population et développement au Maroc, Royaume du Maroc, Centre d'Etudes et de Recherches Démographiques, 121-129, disponível em < https://www.hcp.ma/file/103148/> (última consulta em outubro de 2017).

DIALMY, Abdessalam, 2009, Vers une nouvelle masculinité au Maroc. Dakar, Codesria.

EL FEKI, S., B. HEILMAN, e G. BARKER (orgs.), 2017, Understanding Masculinities: Results from the International Men and Gender Equality Survey (IMAGES) - Middle East and North Africa. Cairo e Washington, DC, UN Women, Promundo, disponível em < https://images mena.org/en/download/ > (última consulta em outubro de 2017).

EMPERADOR BADIMON, Montserrat, 2009, "El movimiento de los diplomados en paro de Marruecos: desafíos a la improbabilidad de una acción colectiva", Revista Internacional de Sociología, 67 (1): 29-58.

GANDOLFI, Paola, 2015, "Multiple families in changing societies in the Maghreb: The case of Morocco", DIFI Family Research and Proceedings, 2015: 7.

JOSEPH, Suad, 1999, "Brother-sister relationships: connectivity, love, and power in the reproduction of patriarchy in Lebanon”, em S. Joseph (org.), Intimate Selving in Arab Families: Gender, Self, and Identity. Syracuse, NY, Syracuse University Press, 113-140.

KAPCHAN, Deborah, 1996, Gender on the Market: Moroccan Women and the Revoicing of Tradition. Filadélfia, University of Pennsylvania Press.

LFARAKH, Abdellatif, 1998, "La famille, ses droits, sa composition et sa structure: Structures familiales et stratégies matrimoniales", em Démographie: Population et développement au Maroc, Royaume du Maroc, Centre d'Etudes et de Recherches Démographiques, 107-119, disponível em < https://www.hcp.ma/file/103148/ > (última consulta em outubro de 2017).

MACLEOD, Arlene Elowe, 1991, Accommodating Protest: Working Women, the New Veiling and Change in Cairo. Nova Iorque, Columbia University Press.

MAHER, Vanessa, 1974, Women and Property in Morocco: Their Changing Relation to the Process of Social Stratification in the Middle Atlas. Cambridge, Cambridge University Press.

MAHMOOD, Saba, 2005, Politics of Piety: The Islamic Revival and the Feminist Subject. Princeton, Princeton University Press.

MERNISSI, Fatema, 2007, L'Amour dans les pays musulmans. Casablanca, Editions Le Fennec.

MERNISSI, Fatema, 2011 [1985], Beyond the Veil: Male-Female Dynamics in Muslim Society. Cambridge, Saqi Books.

MIR-HOSSEINI, Ziba, 2000 [1993], Marriage on Trial: Islamic Family Law in Iran and Morocco. Londres, I. B. Tauris Publishers.

NEWCOMB, Rachel, 2009, Women of Fes: Ambiguities of Urban Life in Morocco. Filadélfia, University of Pennsylvania Press.

PERKINS, Elisa, 2004, “The 2004 Mudawwana reforms and the problem of Moroccan masculinity", Al-Raida, 21 (104-105): 99-101. 
RACHIK, Hassan, et al., s.d. [2005], Rapport de synthèse de l'enquête nationale sur les valeurs (50 ans de développement humain au Maroc et perspectives pour 2025), s.1., disponível em < http://www.abhatoo.net.ma/content/download/17264/306787/version/1/file/Rappor $\mathrm{t}+\mathrm{de}+$ synth\%C3\%A8se+de+1\%E2\%80\%99enqu\%C3\%AAte+nationale+sur+les +va leurs.pdf $>$ (última consulta em outubro de 2017).

RAMíREZ, Ángeles, 2005-2006, "Paradoxes et consensus: le long processus de changement de la Moudawwana au Maroc", L'Année du Maghreb, II, 2005-2006: 23-34, disponível em $<$ http://journals.openedition.org/anneemaghreb/76\#article-76> (última consulta em outubro de 2017).

SILVA, Maria Cardeira da, 1999, Um Islão Prático: O Quotidiano Feminino em Meio Popular Muçulmano. Oeiras, Celta Editora.

VERMEREN, Pierre, 201 1, Le Maroc de Mohammed VI: La transition inachevée. Paris, La Découverte.

ŽVAN-ELliOT, Katja, 2015, Modernizing Patriarchy: The Politics of Women's Rights in Morocco. Austin, University of Texas Press.

ŽVAN-ELLIOT, Katja, 2017, “(Dis)Empowering education: the case of Morocco", Urban Anthropology, 44 (1-2): 1-42. 